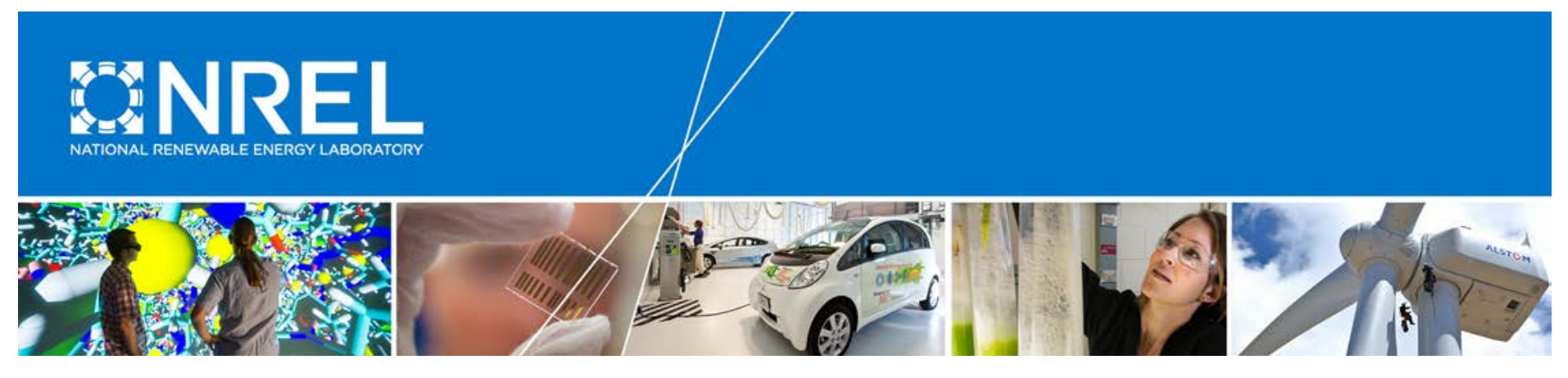

\title{
An Overview of North American Hydrogen Sensor Standards
}

K. O'Malley

SRA International, Inc.

H. Lopez

UL LLC

J. Cairns

CSA Group

R. Wichert

Professional Engineering, Inc.

C. Rivkin, R. Burgess, and W. Buttner National Renewable Energy Laboratory

NREL is a national laboratory of the U.S. Department of Energy Office of Energy Efficiency \& Renewable Energy Operated by the Alliance for Sustainable Energy, LLC

This report is available at no cost from the National Renewable Energy Laboratory (NREL) at www.nrel.gov/publications.

Technical Report

NREL/TP-5400-62062

August 2015

Contract No. DE-AC36-08GO28308 


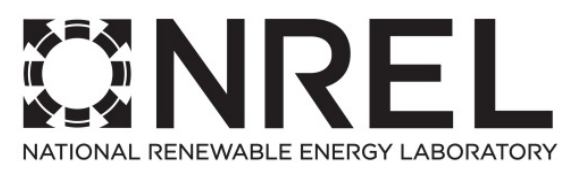

\title{
An Overview of North American Hydrogen Sensor Standards
}

\author{
K. O'Malley
}

SRA International, Inc.

H. Lopez

UL LLC

J. Cairns

CSA Group

R. Wichert

Professional Engineering, Inc.

C. Rivkin, R. Burgess, and W. Buttner National Renewable Energy Laboratory

Prepared under Task No. HT12.7210

NREL is a national laboratory of the U.S. Department of Energy Office of Energy Efficiency \& Renewable Energy Operated by the Alliance for Sustainable Energy, LLC

This report is available at no cost from the National Renewable Energy Laboratory (NREL) at www.nrel.gov/publications.

National Renewable Energy Laboratory 15013 Denver West Parkway Golden, CO 80401

303-275-3000 • www.nrel.gov

\section{Technical Report} NREL/TP-5400-62062

August 2015

Contract No. DE-AC36-08G028308 


\title{
NOTICE
}

This report was prepared as an account of work sponsored by an agency of the United States government. Neither the United States government nor any agency thereof, nor any of their employees, makes any warranty, express or implied, or assumes any legal liability or responsibility for the accuracy, completeness, or usefulness of any information, apparatus, product, or process disclosed, or represents that its use would not infringe privately owned rights. Reference herein to any specific commercial product, process, or service by trade name, trademark, manufacturer, or otherwise does not necessarily constitute or imply its endorsement, recommendation, or favoring by the United States government or any agency thereof. The views and opinions of authors expressed herein do not necessarily state or reflect those of the United States government or any agency thereof.

This report is available at no cost from the National Renewable Energy Laboratory (NREL) at www.nrel.gov/publications.

Available electronically at SciTech Connect http:/www.osti.gov/scitech

Available for a processing fee to U.S. Department of Energy and its contractors, in paper, from:

\author{
U.S. Department of Energy \\ Office of Scientific and Technical Information \\ P.O. Box 62 \\ Oak Ridge, TN 37831-0062 \\ OSTI http://www.osti.gov \\ Phone: 865.576.8401 \\ Fax: 865.576.5728 \\ Email: reports@osti.gov
}

Available for sale to the public, in paper, from:

\author{
U.S. Department of Commerce \\ National Technical Information Service \\ 5301 Shawnee Road \\ Alexandria, VA 22312 \\ NTIS http://www.ntis.gov \\ Phone: 800.553 .6847 or 703.605 .6000 \\ Fax: 703.605.6900 \\ Email: orders@ntis.gov
}




\section{Acknowledgments}

The authors want to acknowledge the contributions provided by Anne Caldas of the American National Standards Institute and Patrick Byrne of FM Approvals. The National Renewable Energy Laboratory's Sensor Laboratory is supported by the U.S. Department of Energy Office of Energy Efficiency and Renewable Energy's Fuel Cell Technologies Office. 


\section{List of Acronyms}

AHJ

ANSI

CaFCP

$\mathrm{CB}$

CEN

CENELEC

CSA

DOE

EN

ETSI

FCEV

FM

$\mathrm{GH}_{2}$

IEC

IFC

ISO

NFPA

NRTL

OSHA

PINS

SDO

UL authority having jurisdiction

American National Standards Institute

California Fuel Cell Partnership

Certification Body

European Committee for Standardization

European Committee for Electrotechnical

Standardization

CSA Group

U.S. Department of Energy

Euro Norme

European Telecommunications Standards Institute

fuel cell electric vehicle

FM Approvals

gaseous hydrogen

International Electrotechnical Commission

International Fire Code

International Organization for Standardization

National Fire Protection Association

nationally recognized testing laboratory

Occupational Safety and Health Administration

project initiation notification system

standards development organization

Underwriters Laboratories 


\section{Executive Summary}

The use of hydrogen as a fuel has already been established in commercial markets, including stationary power systems (e.g., backup power) and fuel-cell-powered industrial trucks (e.g., forklifts), and further growth is expected with the pending release of hydrogen-powered fuel cell electric vehicles (FCEV) for the consumer market. The hydrogen infrastructure, including fueling facilities, repair garages, storage, and transport, must now expand to accommodate FCEVs. However, numerous barriers exist that impede hydrogen infrastructure implementation; one critical barrier is the permitting of new hydrogen facilities. Codes and standards are important in ensuring safety and encouraging commercialization. The availability of components certified to national standards, including safety sensors designed to detect unintended hydrogen releases, can facilitate the design and permitting of hydrogen facilities. The aim of the report is to facilitate hydrogen infrastructure implementation by providing:

- Authorities having jurisdiction and other stakeholders with a concise summary of sensor standards and the acceptable marks provided by nationally recognized testing laboratories applied to a product upon authorization by the respective standards development organization

- Component manufacturers, especially sensor manufacturers, guidance on pertinent standards for their technologies and the certification process

- Guidance to facility stakeholders on certification requirements associated with hydrogen safety sensors.

An overview of the main North American codes and standards associated with hydrogen safety sensors is provided. The distinction between a code and a standard is defined, and the relationship between standards and codes is clarified, especially for those circumstances where a standard or a certification requirement is explicitly referenced within a code. The report identifies three main types of standards commonly applied to hydrogen sensors (interface and controls standards, shock and hazard standards, and performance-based standards). The certification process and a list and description of the main standards and model codes associated with the use of hydrogen safety sensors in hydrogen infrastructure are presented. 


\section{Table of Contents}

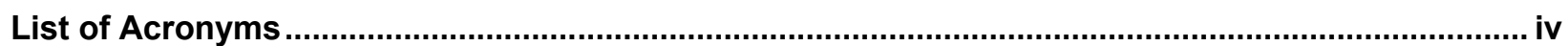

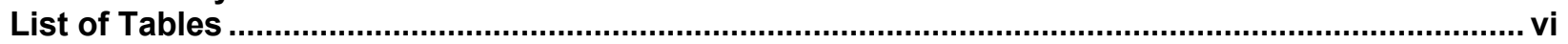

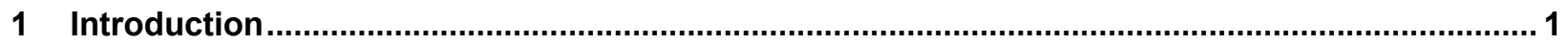

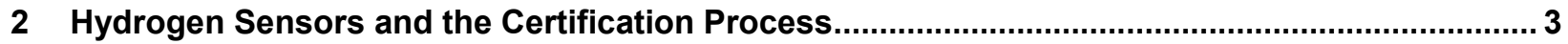

2.1 History of Hydrogen Sensors in Hydrogen Infrastructure ...................................................... 3

2.2 Coordination and Development of Standards in North America .............................................. 4

2.3 Overview of "Certification," "Approval," and "Listing" ....................................................... 6

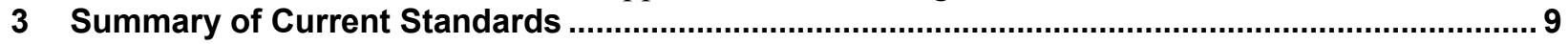

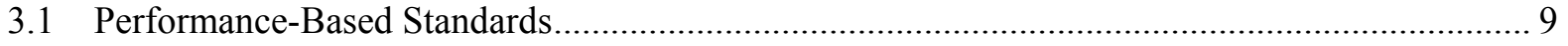

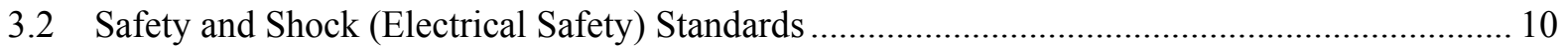

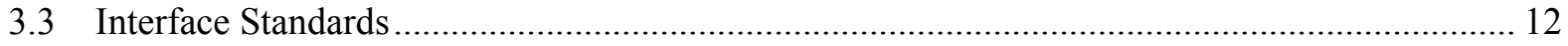

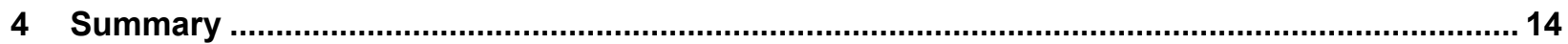

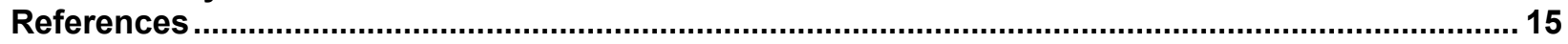

Appendix A: IFC 2012 and NFPA 2 Hydrogen Sensor Requirements ........................................ 17

\section{List of Tables}

Table 1. Certification Directories for Selected NRTLs ....................................................................... 8 


\section{Introduction}

The U.S. Department of Energy's (DOE's) Fuel Cell Technologies Office has taken the lead in supporting the development and deployment of hydrogen as an alternative energy source in the United States [1]. The Fuel Cell Technologies Office supports DOE's mission to ensure the United States' security and prosperity by addressing energy and environmental challenges through transformative science and technology solutions [2]. The use of hydrogen as a fuel has already been established in commercial markets, including stationary power systems (e.g., backup power) and fuel-cell-powered industrial trucks (e.g., forklifts). The growth of these markets is driving the development of hydrogen infrastructure, including transport and production capability, on-site storage, and on-site dispensers [3]. The use of hydrogen as an alternative fuel will continue to grow with the deployment of light-duty road vehicles [4]. Automobile manufacturers in North America, Europe, and Asia project a 2015 release of commercial fuel cell electric vehicles (FCEVs) for the general consumer market, initially in select areas, but with much broader market penetration expected by 2025 [5].

The hydrogen infrastructure must expand to accommodate the projected FCEV market growth. Although the implementation of hydrogen infrastructure is not proceeding uniformly on a national basis, there are state-supported initiatives to assure that the necessary hydrogen fueling facilities are available for the consumer market $[6,7,8]$. One example is in the state of California, where the California Air Resources Board, California Energy Commission, and California Fuel Cell Partnership (CaFCP) are supporting implementation of hydrogen fueling stations throughout the state [6]. However, numerous barriers exist that impede hydrogen infrastructure implementation; one critical barrier is the permitting of new hydrogen fueling facilities. The use of hydrogen as a consumer or industrial fuel is relatively new, and until recently, was not widespread. Accordingly, authorities having jurisdiction (AHJs) have limited experience in dealing with hydrogen, thus necessitating a case-by-case assessment for each deployment, which may require an external, independent, and costly engineering review. While the permitting process is expected to accelerate as a track record of successful commissioning and operation of hydrogen facilities is established, it still remains a major bottleneck in hydrogen deployment.

The availability of components certified to national standards, including safety sensors designed to detect unintended hydrogen releases, can facilitate the design and permitting of hydrogen facilities. The International Fire Code (IFC), 2009 edition [9] and 2012 edition [10], and the National Fire Protection Association (NFPA) 2, Hydrogen Technologies Code [11] have mandated the use of hydrogen safety sensors in hydrogen operations. The IFC has explicit requirements for hydrogen sensors and flammable detection in specific areas, namely for fuel dispensers and in repair facilities. Similarly, NFPA 2 explicitly mandates the use of sensors for various hydrogen operations, including dispensing. Thus, the use of sensors will be mandated by enforceable code if either IFC 2009/2012 or NFPA 2 is adopted by a local jurisdiction. Adoption can be either directly or by reference. For example, the 2010 California Fire Code references the 2009 IFC, thus the sensor requirements within the IFC have become codified in the state of California. The majority of jurisdictions in the United States have adopted the IFC, although not necessarily the most recent edition. Furthermore, Section 2311.7.2.1.1 of the IFC 2012 edition specifically states that the sensors are to be labeled and listed to Underwriters Laboratories (UL) standard UL 864, Control Units and Accessories for Fire Alarm Systems, or UL 2017, General- 
Purpose Signaling Devices and Systems, and UL 2075, Gas and Vapor Detectors and Sensors. NFPA 2 also requires that gas detection equipment shall be listed or approved, although specific standards are not specified. It is expected that the sensor requirements of the IFC and NFPA 2 will become more widespread in the United States as jurisdictions adopt the recent editions of the IFC. Furthermore, it has been proposed that the next edition of the IFC shall specifically reference NFPA 2, thereby incorporating the requirements of NFPA 2 into the IFC. Details on the IFC and NFPA sensor requirements are provided in Appendix A.

There are three main categories of standards associated with hydrogen safety sensors: interface and controls standards, shock and hazard (electrical safety) standards, and performance-based standards. Sensors for use in hazardous environments may require safety certifications such as Class 1, Division $2^{1}$ certification [e.g., American National Standards Institute (ANSI)/International Society of Automation ISA 12.12.01, Nonincendive Electrical Equipment for Use in Class I and II, Division 2 and Class III, Divisions 1 and 2 Hazardous (Classified) Locations, or other electrical safety standards accepted by the AHJ]. In addition to electrical safety standards, there are performance-based standards for gas sensors (e.g., UL 2075, Gas and Vapor Detectors and Sensors, CSA Group (CSA) Standard C22.2, No. 152, Performance of Combustible Gas Detection Instruments, and FM Approvals (FM) Standard 6310/6320 Approval Standard for Combustible Gas Detectors). There are presently no standards specifically for hydrogen sensors, but because hydrogen is a combustible gas, UL 2075; CSA C22.2, No 152; and FM 6310/6320 would apply. Although these standards are not specific to hydrogen, the IFC 2009/2012 editions have, for several applications, mandated that hydrogen safety sensors be listed to UL 2075. However, as of this report, there are no commercially available hydrogen sensors currently listed to UL 2075. Combustible gas sensors listed to FM 6310 are, however, commercially available. Because hydrogen has been a common industrial process gas for many years, combustible gas sensors certified for use in Class I, Division 2 hazardous locations are commercially available.

This report pertains specifically to standards relating to the use and operation of hydrogen safety sensors in North America. Although this primarily encompasses standards developed by North American standards development organizations (SDOs), international standards regularly accepted by AHJs and used by sensor manufacturers will be included. The report also provides a summary of the certification process. The aim of the report is to facilitate hydrogen infrastructure implementation by providing:

- AHJs and other stakeholders with a concise summary of sensor standards and the acceptable marks provided by nationally recognized testing laboratories (NRTLs) applied to a product upon authorization by the respective Certification Body (CB)

- Component manufacturers, especially sensor manufacturers, guidance on pertinent standards for their technologies and the certification process

- Guidance to facility stakeholders on certification requirements associated with hydrogen safety sensors.

\footnotetext{
${ }^{1}$ Class I refers to environments where flammable gas may be present, and Division 2 (or Zone 2) indicates that the flammable gas or vapor would be present only in abnormal situations, for example, an unintended release. Class 1 or Zone 1 indicates that flammable gas mixtures are likely to be present in normal operations.
} 


\section{Hydrogen Sensors and the Certification Process}

\subsection{History of Hydrogen Sensors in Hydrogen Infrastructure}

To advance the development of FCEVs and hydrogen infrastructure, DOE and several states have supported numerous demonstration projects. Key examples include the DOE's National Hydrogen Learning Demonstration [12] and the efforts of the CaFCP [13]. The National Hydrogen Learning Demonstration oversaw the installation of 25 hydrogen fueling stations demonstrating various hydrogen production technologies, including on-site production through natural gas reformation and water electrolysis, as well as delivered liquid hydrogen and delivered compressed hydrogen through tube trailers and pipelines. The CaFCP, in conjunction with the California Air Resources Board and the California Energy Commission, initiated the development of hydrogen infrastructure in California. One of the first hydrogen facilities built in the United States in support of FCEVs was at the CaFCP's headquarters in Sacramento, California [13]. Without a history of hydrogen facility installations to reference, the CaFCP commissioned a study to determine the appropriate sensor safety system and leaned toward conservative engineering, adding complexity and cost [14]. The facility safety system design included combustible-gas sensors. Although the sensors were listed to electrical safety standards (e.g., FM 3600, Approval Standard for Electrical Equipment for Use in Hazardous (Classified) Locations - General Requirements; FM 3615, Approval Standard for Explosionproof Electrical Equipment General Requirements; and FM 3810, Approval Standard for Electrical Equipment for Measurement, Control, and Laboratory Use), and a sensor performance standard (e.g., FM 6310/6320), they were not listed to the performance-based standard (e.g., UL 2075) or interface standards (e.g., UL 864 or UL 2017) as specified in IFC 2009. The use of sensors listed to performance standards has been codified by the state of California through reference to the IFC by the California Fire Code. Because no hydrogen sensor is currently listed to UL 2075, the sensor safety system for the CaFCP FCEV facility had to be approved by the AHJ, which resulted in delays and expense. AHJ "approval" can waive or modify code requirements in response to information or by request of the parties doing the work. Such approvals might require engineering analysis, backup documentation, or other evidence showing alternate means of providing the required levels of safety, any of which will cause delays and add cost to the permitting process. Typically it is necessary that alternative means must show an equivalent or greater level of safety relative to the prescriptive code requirements. Thus, the IFC sensor requirements are not absolute but provide the basis to facilitate routine compliance with the regulations.

A large number of hydrogen stations and facilities have been built since the early demonstrations, and more are planned. For example, Toyota and Honda have built hydrogen facilities for hydrogen fueling and hydrogen vehicle maintenance. Industrial gas companies like Air Products, along with traditional energy companies including Shell, Chevron, and BP, have constructed fueling stations for both demonstration and public use applications. These demonstration projects still had to meet safety and performance requirements and required AHJ approval before permitting. Facilities that service hydrogen vehicles were also erected since the construction of the CaFCP facility, and their safety systems were largely modeled on those designs initially set at the CaFCP facility. Many hydrogen facilities and stations constructed before the publication of hydrogen-specific codes used sensors compliant with Class 1, Division 2 listings from ANSI/ISA 12.12.01 or other shock and hazard standards. None of these facilities, 
however, used sensors certified to UL 2075, due in part to the lack of sensors certified to this standard. Instead, the hydrogen sensors in these initial infrastructure developments were selected because they were either certified to another performance standard deemed acceptable by the AHJ, were used in other industrial hydrogen operations, or were otherwise shown to satisfy the safety concerns of the facility managers and AHJs.

\subsection{Coordination and Development of Standards in North America}

Codes and standards are important in ensuring safety and encouraging commercialization. Often treated as synonymous or referred to together as codes and standards, there is a distinction between a code and a standard. A model code is a document developed by industry experts and informed stakeholders for others to follow. The model code is typically written in a way that can be adopted into law, and once adopted, it is legally binding. Properly speaking, a document is codified, that is, becomes a code, only upon adoption by a local jurisdiction. Thus, by definition, a code is legally enforceable. Although called the International Fire Code, the IFC would not be enforceable until formal adoption by a jurisdiction. Similarly, NFPA 2 would not be codified until adopted by a jurisdiction. Without adoption, the requirements specified in the IFC or NFPA could not be legally imposed upon stakeholders. For this reason, the IFC and NFPA 2 are often referred to as model codes that can be adopted by a jurisdiction. The adopting jurisdiction would have the option to accept completely the model code document or to change specific requirements within the document.

A standard is a document that establishes uniform engineering or technical criteria, methods, processes, and practices. A simplified definition of a standard is a document that tells you (or systems, machines, etc.) how to do or say or make or test something [15]. A standard is typically narrower in scope and more specific than a code and contains specific requirements for product compliance. Compliance and certification to most standards are voluntary and are only enforceable upon incorporation into a particular code or regulation by reference. Thus, if a standard is referenced in a jurisdiction's code, the jurisdiction is legally mandated to use products listed to that standard. However, certification requirements specified within a code may be waived if approved by the AHJ. For example, the IFC may require certification of sensors to a specific standard but also explicitly allow the use of approved technology; in other words, the use of noncertified technologies may be used for a specific application provided they are approved by the AHJ. Such approval for a waiver might require engineering analysis, backup documentation, or other evidence showing alternate means of providing equivalent levels of safety; it may be the only viable option for situations where certified components are unavailable. This can be a costly and time-consuming process, often performed on a case-bycase basis. However, even if not mandated, certification to a standard assures end-users that the product meets the safety or performance requirements as specified in the standard. Thus, product certification plays an important role in simplifying and expediting the permitting process and facilitating community acceptance.

There are several organizations and entities that work together to ensure public safety through the development of consensus-based product safety standards and certification of products to these requirements. There is a natural hierarchy in the world of standards development with organizations working cooperatively to clearly outline the scope of work and ensuring coordination at the regional, national, and international levels. In the United States, ANSI is the national coordinating body. Through accreditation of an SDO within the United States, ANSI 
ensures that the SDO and its processes meet the requirements for transparency, balance, consensus, and due process. ANSI coordinates the scope of U.S. standards development so that there are no conflicting requirements for the same product design. ANSI also strives to harmonize domestic and international standards requirements to ensure import and export of safe and quality products for the United States.

There are over 200 SDOs in the United States accredited by ANSI to develop technical, performance, and safety standards for a variety of products and services. ANSI utilizes a Project Initiation Notification System (PINS) to coordinate development activities. Submission of a PINS form through ANSI is the first step in the process for development of a standard. This step involves public notification of an SDO's intent to begin working on development of a standard for a particular product or service. During a 30-day review period, stakeholders are notified and provided the opportunity to comment. The PINS tool is used to manage the coordination of standards development activity between multiple SDOs and eliminate duplication of effort and development of conflicting requirements. Any comments received during this phase must be resolved through documented ANSI procedures and may include revisions to the proposed project scope.

Accredited SDOs develop standards utilizing a consensus-based process approved by ANSI. Most SDOs focus on specific industries or sectors; key SDOs involved in hydrogen and fuel cell efforts include CSA [16], UL [17], and FM [18]. CSA has over 90 years of experience in writing standards for product areas, including gas, plumbing, electrical, appliances, hazardous locations, medical, lighting, construction, alternative energy vehicle technologies, and personal protection equipment. UL has extensive experience in developing safety, equipment, and performance testing standards for the construction; electronics; and environmental, health protection, and safety; and telecommunications industries. FM Approvals is a division of FM Global, a comprehensive commercial and industrial property insurance provider that focuses on testing and certification of property loss prevention products meeting rigorous loss prevention standards.

Other SDOs have developed standards used in the combustible gas sensor industry. The International Electrotechnical Commission (IEC) develops international standards [19] that are often recognized in the United States. IEC 60079, Parts 0 to 34, is a series of standards for electrical equipment and detectors for use in explosive environments, many of which are model standards for other SDO standards, including domestic SDOs. Internationally, a European Standard (EN) is a standard that has been adopted by one of the European standardization organizations, the European Committee for Standardization (CEN) or the European Committee for Electrotechnical Standardization (CENELEC) for electrotechnology and the European Telecommunications Standards Institute (ETSI) for telecommunication [20]. "EN" is an abbreviation for "Euro Norme" (norme is French for "standard"). EN standards may also be equivalently listed as IEC standards. When this occurs, a product may contain multiple prefixes, indicating the standards that it meets. However, some EN standards are adopted for use only in Europe, and thus are not necessarily relevant for U.S. markets. Similarly, Conformité Européenne $(\mathrm{CE})$ certification denotes that a product meets certain standards required in the European Union. Products with the CE mark are typically self-certified, but companies are required to maintain documentation to verify compliance. Manufacturers may opt to certify their product designs to both U.S. and international standards so as broaden their markets. 


\subsection{Overview of "Certification," "Approval," and "Listing"}

Product certification is the process by which the product design undergoes specific evaluation and testing procedures to ensure that the design meets all of the requirements detailed in a standard. The term "certification" is used with respect to a specific standard. "Certification" and "listed" can be and are often used interchangeably, but there are subtle differences. "Product listing" refers to the list published by a CB or NRTL of products certified to a specific standard. Because all listed product designs will be certified and the CB or NRTL will list all products it has certified, the distinction is minor. It is noted that ANSI does not formally endorse the use of the term "listed," but prefers the term "certified" to indicate that a product design has been tested and evaluated by a CB or NRTL to meet the requirements of a standard [21]. Furthermore, ANSI reserves the term "approved" to refer to a standard that it recognizes and asserts that "approved" should not be used as synonymous with "certified" [21]. This policy concurs with some CBs or NRTLs (e.g., UL, CSA) that explicitly state that the term "approved" should never be used as synonymous with "certified" when referring to product designs the CB or NRTL has certified. However, the distinction between the use of the terms "certified" and "approved" is not universal. For historic reasons, FM still uses the term "approved" to indicate a product design certification to FM standards [18].

The certification process is initiated by the manufacturer and includes an initial application where the product design is reviewed by a CB or NRTL to see if it meets the requirements specified in the standard. The CB or NRTL typically assigns a file number for each client company that stakeholders can use to verify that the company's products are indeed certified. CBs are organizations accredited by ANSI and other accrediting bodies. NRTLs are organizations that have been accredited by the U.S. Department of Labor's Occupational Safety and Health Administration (OSHA) as meeting necessary qualifications to test and ensure that specific equipment and materials meet specific safety standards and are safe for use [22]. NRTLs are authorized to test specific product categories to specific standards published by recognized SDOs and included in OSHA's NRTL Program. It is important to note that the development of a standard and the certification of a product design to that standard are distinct functions and that a SDO can but does not necessarily function as CB or NRTL. However, numerous SDOs, such as FM, UL, and CSA, are also accredited CBs and NRTLs, and it is the CB and NRTL that are authorized to do product design certification. "NTRL" is a term associated with OSHA and is valid for U.S.-based standards. In Canada, an agency can be accredited by the Standards Council of Canada to test products as a testing laboratory and to certify a product as a certification organization. All three agencies are certified as NRTLs by OSHA to test and certify products to U.S. standards. Additionally, all three are accredited as both testing laboratories and certification organizations by the Standards Council of Canada to test and certify products to Canadian standards.

The CB or NRTL subjects the product design to all the required tests prescribed by the standard. The CB or NRTL then analyzes the results, and if the product design meets all applicable requirements in the standard, it is granted the certification. In order for product designs to maintain their certification, a maintenance or follow-up program must be established to ensure that the product design continues to meet requirements after the initial evaluation. While CBs or NRTLs maintain extensive facilities for product certification, it is also possible to utilize data obtained from accredited third-party facilities (e.g., UL's Third-Party Test Data Program [23]). 
The use of third-party testing can be a cost-effective way to streamline the certification process. However, not all CBs or NRTLs will accept third-party data for product design certification.

In addition to products being certified, products can also be "component certified," "classified" or "recognized" by CBs or NRTLs. A "classified" product has been evaluated by an NRTL but only in regard to certain properties, such as a limited range of hazards or suitability for use under limited or special conditions. The "component certified" or "recognized" distinction typically refers to component parts that are part of a larger product or system. The use of recognized components can streamline the end-product evaluation and certification of a product design.

CBs and NRTLs typically assign a certification mark that is displayed on a product certified to a specific standard $[24,25]$. The visual certification "mark" or "label" is often required; for example, the IFC 2009 explicitly states that sensors be "listed and labeled" to UL 2075. Upon certification, the CB or NRTL authorizes the client to affix the CB's or NRTL's mark to the product. The certification mark is one of the easiest ways to verify if a product has been certified. The mark typically contains several elements, including the unique CB or NRTL marking, the product category code, and other qualifying information. Representative certification marks from leading CBs and NRTLs are shown below. These are the most generic images; many SDOs have variations on their marks to indicate product design certification in Canada, the United States, Europe, or Asia.

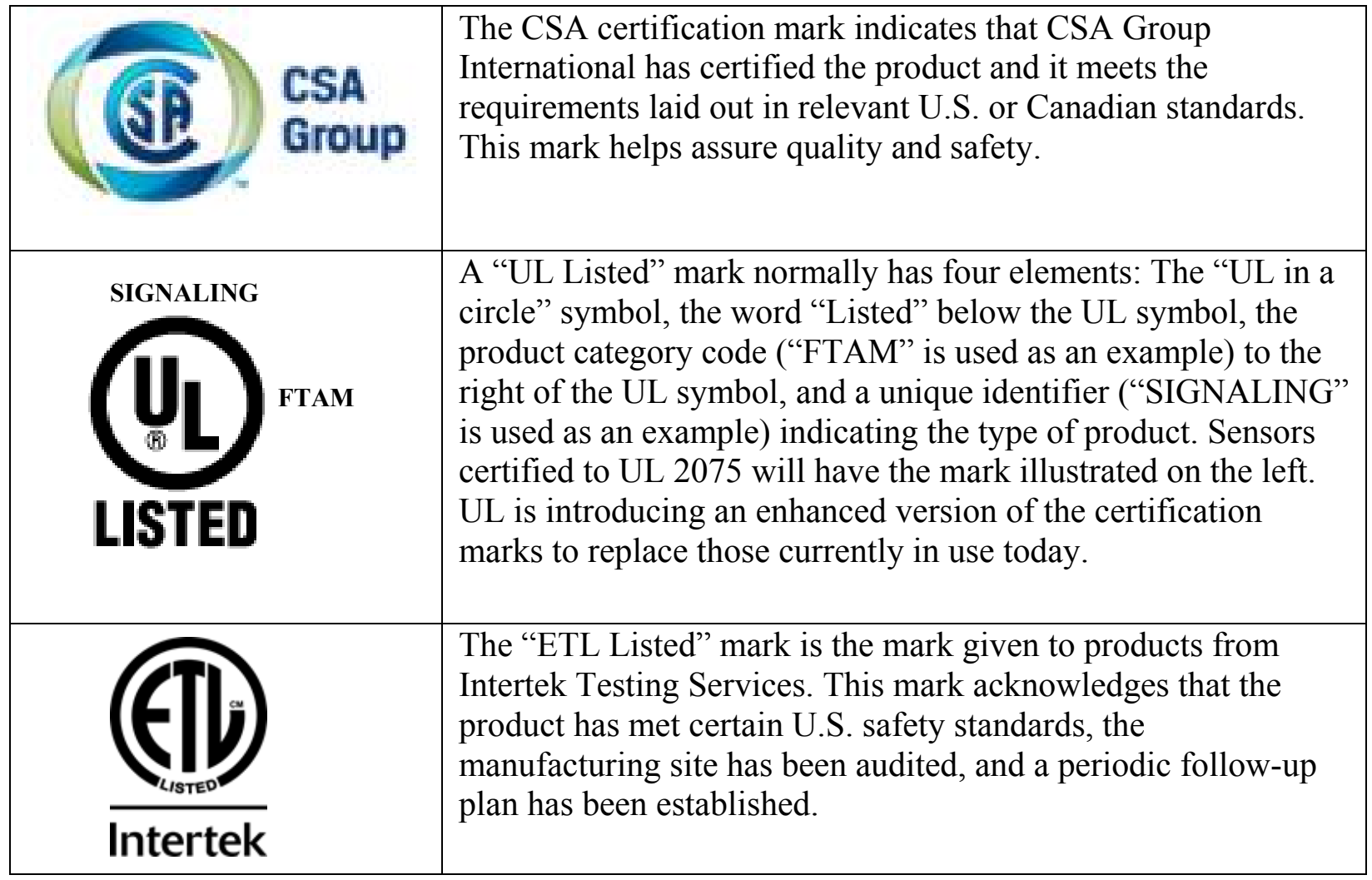




The "FM Approved" mark indicates that the product has been
objectively tested and the product meets the requirements laid
out in relevant U.S. and Canadian standards. The manufacturer
requests FM Approvals to review, test, and audit its product,
resulting in a report and the "FM Approved" mark and listing.
Follow-up audits are scheduled to ensure quality and safety.

Each CB or NRTL is responsible for organizing and maintaining a database that houses information on product listings and their certifications. These databases are a tool to help verify certification, classification, or recognition of product designs. The databases thus provide a means to protect against counterfeit labels or fraudulent certification claims by providing endusers an easy resource to verify that a product displaying a CB or NRTL label is indeed listed (certified) by that CB or NRTL. The databases for representative CB or NRTLs can be accessed through the links listed in Table 1. Many of these databases have several search options, allowing users to look for companies (sometimes through the Company Code assigned by the CB or NTRL), class numbers or category codes or through product category codes.

Table 1. Certification Directories for Selected NRTLs

\begin{tabular}{ll}
\hline NRTL & Online Certification Directory \\
\hline CSA Group & http://www.csagroup.org/us/en/services/testing-and-certification/certified-product-listing \\
UL & $\underline{\text { http://database.ul.com/cgi-bin/XYV/template/LISEXT/1FRAME/index.htm }}$ \\
FM Approvals & $\underline{\text { http://www.approvalguide.com/CC host/pages/public/custom/FM/login.cfm }}$ \\
Intertek & $\underline{\text { http://www.intertek.com/directories/ }}$ \\
IEC & $\underline{\text { www.iec.ch }}$ \\
\hline
\end{tabular}




\section{Summary of Current Standards}

Three main categories of standards associated with hydrogen safety sensors have been identified in this report. They are performance-based standards, shock and hazard (electrical safety) standards, and interface and controls standards. The main standards developed, recognized, or used in North America (United States and Canada) are summarized below. More information on the various standards can be obtained from the specific SDO. Many SDOs develop "guide cards" that provide a brief overview of the standard. The guide cards (or analogous systems for other SDOs) provide stakeholders with an invaluable tool. The guide cards assist sensor developers in identifying appropriate standards for their products. For end-users, AHJs, and other regulators, the guide cards provide a scope of the technical requirements in the standard.

\subsection{Performance-Based Standards}

Numerous SDOs have developed standards that relate to the performance requirements for hydrogen sensors. The following standards are used within the United States to assure performance of the end product(s):

\section{- UL 2075: Gas and Vapor Detectors and Sensors}

Synopsis: UL 2075 is referenced in the IFC 2009 and 2012 editions; thus, sensors certified to UL 2075 or otherwise approved by the AHJ must be used. UL 2075 includes general performance requirements for gas sensors and detectors. These requirements cover toxic and combustible gas and vapor detectors and sensors intended to be portable or employed in indoor or outdoor locations in accordance with the National Electrical Code (NFPA 70). A gas detector and/or sensor and/or vapor detector, as covered by these requirements, consists of an assembly of electrical components coupled with a sensing means inside a chamber, or by separate components, to detect toxic and/or combustible gases or vapors. The detector includes provisions for connection to a source of power and signaling circuits.

\section{- CSA C22.2 No. 152-M1984: Combustible Gas Detection Instruments}

Synopsis: Products evaluated to this standard are applied in areas that are or could be a hazardous location due to the presence of an explosive gas atmosphere (a mixture with air, under atmospheric conditions, of flammable substances in the form of gas, vapor, or mist in which, after ignition, combustion spreads throughout the unconsumed mixture). This standard covers portable gas detection equipment used by maintenance personnel, first responders, utilities, or any other instance where personnel need to verify the presence or absence of combustible gases. This standard also covers field-installed gas detectors used to monitor an environment, sound an alarm, shut down equipment, or activate ventilation systems designed to remove or dilute the combustible gas atmosphere. Certification to CSA C22.2 No. 152-M1984 also requires that the sensor should be certified for operation in Class I, Division 1.

\section{- FM 6310/6320: Approval Standard for Combustible Gas Detectors}

Synopsis: FM 6310/6320 is widely used for industrial applications and addresses performance requirements. This standard is concerned with the details of construction, 
performance, and testing of portable, mobile, and stationary electrical instruments that sense the presence of combustible gas or vapor concentrations in air. This standard considers the suitability of the instruments or parts thereof for use in Class I, hazardous (classified) locations as defined by the National Electrical Code (NFPA 70). FM Approval Standard 6310/6320 is essentially identical to EN/IEC 60079-29-1 [22]. One minor difference includes an increased maintenance program requirement in FM 6310/6320. Certification to FM 6310/6320 also requires that the sensor should be certified for operation in Class I, Zone 1, or Division 1.

There are also international standards on hydrogen sensor performance, including the following. These are not extensively applied in U.S. applications.

\section{- ISO 26142: Hydrogen Detection Apparatus - Stationary Applications}

Synopsis: ISO 26142:2010 defines the performance requirements and test methods for hydrogen detection apparatus that is designed to measure and monitor hydrogen concentrations in stationary applications. The provisions in ISO 26142:2010 cover the hydrogen detection apparatus used to achieve the single and/or multilevel safety operations, such as nitrogen purging or ventilation and/or system shutoff corresponding to the hydrogen concentration. The requirements applicable to the overall safety system, as well as the installation requirements of such apparatus, are excluded. ISO 26142:2010 sets out only the requirements applicable to a product standard for hydrogen detection apparatus, such as precision, response time, stability, measuring range, selectivity, and poisoning.

In summary, UL 2075 covers specific construction requirements for the end product that deal with both fire and shock, as well as for reliability of the end product(s). The test program (e.g., test methods and results) of UL 2075 differs from that of both CSA C22.2 No. 152-M1984 (Reaffirmed 2011) and FM 6310/6320. Each of these standards requires compliance to additional standards that address construction requirements, such as CSA C22.2 No. 142 or FM3810. The testing per UL 2075 is to verify compliance with the construction of the end product, but also generates test data to support the end-product performance when tested against the intended gas(es) that the device(s) are intended to detect. The tests in CSA C22.2 No. 1502-M1984 are similar to the tests in FM 6310/6320 because these standards are similar to the EN 60079-29-1 and EN 60079-29-1-4 requirements. Both the CSA C22.2 No. 152-M1984 and FM 6310/6320 standards only have general construction details for meters and indications, alarm functions, trouble signals, batteries, control, and adjustment, while UL 2075 has more detailed construction requirements such as electrical spacing, maximum temperature rise of components, displays, enclosure material, etc., not provided in either CSA C22.2 No. 152-M1984 or FM 6310/6320. The CSA C22.2 No. 152-M1984 standard is associated with certification of end products for use in Canada whereas the UL 2075 standard is intended for end products for use in the United States.

\subsection{Safety and Shock (Electrical Safety) Standards}

- UL 61010-1: Safety Requirements for Electrical Equipment for Measurement, Control, and Laboratory Use - Part 1: General Requirements 
Synopsis: UL 61010-1 is essentially identical to IEC 61010-1, which specifies general safety requirements for electrical equipment intended for professional, industrial process, and educational use, any of which may incorporate computing devices.

\section{- UL 60079: Explosive Gas Atmospheres}

Synopsis: ANSI/UL 60079 is essentially identical to IEC 60079, which specifies requirements for construction, testing, and marking of Group II electrical apparatus with type of protection " $n$ " intended for use in Class I, Zone 2 hazardous (classified) locations as defined by the National Electrical Code (ANSI/NFPA 70).

\section{- IEC 60079: Explosive Atmospheres}

IEC 60079 specifies the general requirements for construction, testing, and marking of electrical equipment and components intended for use in explosive atmospheres, including the following:
- Class I, Zone 0
- Class I, Zone 1
- Class I, Zone 2.

IEC 60079 pertains to explosive atmospheres and consists of Parts 1-34. Some of the most important sections for hydrogen sensors are:

○ IEC 60079-0: Explosive Atmospheres - Part 0: Equipment - General Requirements

- IEC 60079-1: Explosive Atmospheres - Part 1: Equipment Protection by Flameproof Enclosures

- IEC 60079-11: Explosive Atmospheres - Part 11: Equipment Protection by Intrinsic Safety

- IEC 60079-15: Explosive Atmospheres - Part 15: Equipment Protection by Type of Protection " $\mathrm{n}$ "

○ IEC 60079-29-1: Explosive Atmospheres - Part 29-1: Gas Detectors Performance Requirements of Detectors for Flammable Gases

- IEC 60079-29-2: Explosive Atmospheres - Part 29-2: Gas Detectors - Selection, Installation, Use and Maintenance of Detectors for Flammable Gases and Oxygen

Many of the IEC standards are identical or nearly identical to standards developed by other SDOs.

\section{- CSA C22.2 No. 152-M1984: Combustible Gas Detection Instruments}

Synopsis: Products evaluated to this standard are applied in areas that are or could be a hazardous location due to the presence of an explosive gas atmosphere (a mixture with air, under atmospheric conditions, of flammable substances in the form of gas, vapor, or mist in which, after ignition, combustion spreads throughout the unconsumed mixture). This standard covers portable gas detection equipment used by maintenance personnel, 
first responders, utilities, or any other instance where personnel need to verify the presence or absence of combustible gases. This standard also covers field-installed gas detectors used to monitor an environment, sound an alarm, shut down equipment, or activate ventilation systems designed to remove or dilute the combustible gas atmosphere.

- FM 3600: Approval Standard for Electrical Equipment for Use in Hazardous Locations

This standard identifies the basis for "approval" (certification) of electrical equipment for use in hazardous (classified) locations. The requirements in the standard are based on consideration of ignition in locations made hazardous by the presence of flammable or combustible materials under normal atmospheric conditions over the ranges:

A. Temperature from $-25^{\circ} \mathrm{C}$ to $+40^{\circ} \mathrm{C}$

B. Oxygen not greater than 21 percent by volume

C. Barometric pressure in the range of 0.8 to $1.1 \mathrm{~atm}$.

These specific conditions may be superseded by other values in an alternative, relevant, specific standard for the type of protection desired.

- FM 3615: Approval Standard for Explosionproof Electrical Equipment General Requirements

This standard contains the basic requirements for the construction and testing of explosion-proof electrical equipment. This standard is expected to be used in conjunction with FM 3600.

- FM 3810: Approval Standard for Electrical Equipment for Measurement, Control and Laboratory Use

This standard states approval (certification) requirements for electrical equipment for measurement, control, and laboratory use. Approval requirements include, but are not limited to, performance requirements, marking requirements, examination of manufacturing facilities, audits of quality assurance procedures, and follow-up programs.

\subsection{Interface Standards}

\section{- UL 864: Control Units and Accessories for Fire Alarm Systems}

Synopsis: UL 864 is referenced in the IFC 2009 and 2012 editions; thus, for those jurisdictions that adopted the IFC, sensors certified to UL 864 (or UL 2017) or approved by the AHJ must be used. These requirements cover discrete electrical control units and accessories for fire alarm systems to be installed in accordance with the NFPA 70 model code titled "National Electrical Code" and in accordance with the NFPA 72 model code, titled "National Fire Alarm Code." The products covered by this standard are intended to be used in combination with other appliances and devices to form a commercial fire alarm system. These products provide all monitoring, control, and indicating functions of the system. 


\section{- UL 2017: Control Units and Accessories for Fire Alarm Systems}

Synopsis: UL 2017 is referenced in the IFC 2009 and 2012 editions; thus, sensors certified to UL 2017 (or UL 864) or approved by the AHJ must be used. These requirements cover signaling devices intended for emergency or non-emergency use, used in indoor and/or outdoor locations, and, where applicable, installed and used in accordance with the National Electrical Code (NFPA 70). Emergency-signaling products covered by these requirements are associated with property and/or life safety and are of a non-fire/non-security alarm nature. These products are evaluated with regard to product safety and to appropriateness of signaling. Non-emergency-signaling products covered by these requirements are not associated with property and/or life safety and are only evaluated relative to product safety.

\section{- FM 3010: Approval Standard for Fire Alarm Signaling Systems}

Synopsis: This standard applies to permanently installed fire alarm signaling systems intended for indoor use in ordinary electrical locations. The equipment covered by this standard connects to other peripheral equipment (initiating, notification, and offpremises) to provide indicating and control functions associated with a commercial fire alarm system in accordance with NFPA 72. Examined products may be complete systems of products intended to provide a capability or feature (e.g., auxiliary power supplies or digital alarm communicator transmitters) that would then be used with an approved fire alarm signaling system. This standard provides the operating basis for alarm signaling and does not cover (other standards apply) initiating and notification devices as well as the use in damp, wet or hazardous (classified) locations. The equipment covered by this standard may be combined with additional standards for use in other areas. 


\section{Summary}

Development and adoption of codes and standards with hydrogen sensor requirements are a crucial element for the successful commercialization of hydrogen and fuel cell technologies, particularly the development of hydrogen infrastructure. Initial infrastructure efforts have been successfully and safely developed, but the lack of codes and standards, as well as certified hydrogen-compatible components including hydrogen sensors, has necessitated the need for AHJ approval on a case-by-case basis, making the process slow, cumbersome, and expensive. Certification and listing of sensors to relevant standards are crucial to improve the permitting of hydrogen stations, helping to reduce the time needed for approval and lowering costs as AHJs can rely on these certifications instead of requiring individual reviews. Development of codes and standards is a coordinated effort among relevant stakeholders and applies to both safety and performance. Certification of products to meet these standards is overseen by CBs or NRTLs and used by manufacturers to demonstrate the safety and performance of their products. This system enables a swifter review in permitting and ensures safety. CB or NRTL certification directories help protect against fraudulent listing claims and potentially unsafe products.

This review of the certification process and the summary of hydrogen sensor standards were performed to assist both sensor developers and manufacturers looking to commercialize hydrogen sensor technology along with AHJs and other stakeholders hoping to accelerate the commercialization of hydrogen and fuel cells, especially those stakeholders without prior experience in hydrogen operations. Increased awareness and knowledge of current hydrogen sensors and the related codes and standards can help reduce current permitting difficulties and work towards the goal of developing hydrogen infrastructure for FCEVs. 


\section{References}

[1] U.S. Department of Energy, “The Department of Energy Hydrogen and Fuel Cells Program Plan" (Washington, D.C., September 2011), http://www.hydrogen.energy.gov/pdfs/program plan2011.pdf.

[2] U.S. Department of Energy, "Mission," accessed May 26, 2015, http://energy.gov/mission.

[3] R. Burgess, W. Buttner, and C. Rivkin, "Codes and Standards Requirements for Deployment of Emerging Fuel Cell Technologies," Technical Report NREL/TP-560052641 (Golden, CO: National Renewable Energy Laboratory, 2011), http://www.nrel.gov/docs/fy12osti/52641.pdf.

[4] Toyota, "Toyota Mirai - The Turning Point," Mirai Fuel Cell Vehicle, accessed June 1, 2015, http://www.toyota.com/mirai/.

[5] U.S. Department of Energy, "An Integrated Strategic Plan for the Research, Development, and Demonstration of Hydrogen and Fuel Cell Technologies" (Washington, D.C.: U.S. Department of Energy, 2011).

[6] California Fuel Cell Partnership, “A California Road Map,” 2013, http://cafcp.org/carsandbuses/caroadmap.

[7] J. Morelle, M. Fronk, J. Love, and D. Seeley. "Developing a Hydrogen Powered Economy in New York State," in HTAC, Washington, DC, 2011.

[8] Hawai'i Hydrogen Initiative, "Infrastructure | H2I," About the Infrastructure, accessed April 25, 2013, http://www.hydrogen2hawaii.com/about/infrastructure/.

[9] International Code Council, "International Fire Code - 2009," 2009, http://publicecodes.cyberregs.com/icod/ifc/2009/.

[10] International Code Council, "International Fire Code - 2012," 2012, http://publicecodes.cyberregs.com/icod/ifc/2012/.

[11] "NFPA 2: Hydrogen Technologies Code," accessed May 27, 2015, http://www.nfpa.org/codes-and-standards/document-informationpages mode $=$ code $\& \operatorname{code}=2 \&$ tab $=$ nextedition .

[12] K. Wipke et al., "National Fuel Cell Electric Vehicle Learning Demonstration Final Report,” Technical Report NREL/TP-5600-54860. (Golden, CO: National Renewable Energy Laboratory, 2012), http://www.nrel.gov/docs/fy12osti/54860.pdf.

[13] California Fuel Cell Partnership, "Station Map," accessed May 26, 2015, http://cafcp.org/stationmap. 
[14] Parsons Brinckerhoff, "Support Facilities for Hydrogen-Fueled Vehicles: Conceptual Design and Cost Analysis Study," Technical Report, Commissioned by CaFCP, (July 2004), accessed 31 October 2013, http://cafcp.org/sites/files/H2VehicleFacilityStudy_0.pdf.

[15] A. Caldas, "What Is an American National Standard? ASME Short Course," 2013.

[16] CSA Group, accessed May 27, 2015, http://www.csagroup.org/us/en/home.

[17] Underwriters Laboratories, accessed May 27, 2015, http://ul.com/.

[18] FM Global, "FM Approvals: Setting the Standard in Third-Party Certification" (FM Global, 2015), http://www.fmglobal.com/page.aspx?id=50000000.

[19] International Electrotechnical Commission "IEC." 2014. www.iec.ch.

[20] European Committee for Standardization, “CEN," 2014, http://www.cen.eu/Pages/default.aspx.

[21] A. Caldas, Personal communication, November 14, 2013.

[22] U.S. Department of Labor, "OSHA's Nationally Recognized Testing Laboratory (NRTL) Program," Nationally Recognized Testing Laboratory Program, accessed May 26, 2015, https://www.osha.gov/dts/otpca/nrtl/.

[23] Underwriters Laboratories, "UL Third-Party Test Data Program," (Underwriters Laboratories, 2013), accessed 15 March, 2013, http://www.ul.com/global/documents/offerings/services/programs/dap/ThirdPartyTestDat aProgram.pdf.

[24] Underwriters Laboratories, "UL Listing and Classification Marks," accessed May 27, 2015, http://ul.com/corporate/marks/ul-listing-and-classification-marks/.

[25] CSA Group, “Certification Marks \& Labels," http://www.csagroup.org/us/en/about-csagroup/certification-marks-labels 


\section{Appendix A: IFC 2012 and NFPA 2 Hydrogen Sensor Requirements}

In North America, the main documents governing mandatory safety requirements in the emerging hydrogen infrastructure are covered by the International Fire Code (IFC) and National Fire Protection Association Code 2 (NFPA 2). The IFC and NFPA are endeavoring to simplify and harmonize their respective documents, in part by eliminating duplicate requirements. Furthermore, the IFC (2014) has explicitly referenced NFPA 2, thereby assuring compliance to the requirements of NFPA 2 by those jurisdictions that adopt the 2014 edition of the IFC. The following is a list of the main sections in the most recently published editions of the IFC and NFPA that specifically cite hydrogen sensor/detector requirements.

\section{From the 2012 International Fire Code ${ }^{2}$ :}

\section{Section 2309 (Motor Fuel-Dispensing and Generation Facilities)}

- 2309.2.2: Listed or approved equipment requirements for detection systems and other components and systems.

\section{Section 2311 (Repair Garages)}

- 2311.7.2: Mandates that a flammable gas detection system be installed in repair garages used for repair of vehicles fueled by non-odorized gases, such as hydrogen and nonodorized liquefied natural gas.

- 2311.7.2.1.1: Mandates listing requirements for gas detection system components, which shall be listed and labeled in accordance with UL 864 or UL 2017. Gas detectors shall be listed and labeled in accordance with UL 2075 for use with the gases and vapors being detected.

\section{From NFPA 2 - Hydrogen Technologies Code:}

The use and maintenance of hydrogen sensors/detectors are explicitly referenced in several locations in NFPA 2. Some of the main references are presented below. Several chapters are listed that have not yet been completed, but that may be developed in future editions of NFPA 2. It is likely that hydrogen detection will be required in several of these chapters; thus, the required use of hydrogen sensors/detectors will expand. Once NFPA 2 is referenced in the next edition of the IFC, NFPA 2 requirements will be mandated in all jurisdictions that adopt the IFC.

\section{Chapter 3: Definitions}

- 3.3.219.2.2: Defines the Gas Detection System as one or more sensors capable of detecting hydrogen at specified concentrations and activating alarms and safety concerns

\section{Chapter 6: General Hydrogen Requirements}

\footnotetext{
${ }^{2}$ IFC 2012 is the most recent edition of the IFC. The hydrogen sensor/detector requirements for IFC 2009 are identical to that of IFC 2012. IFC 2009 formed the basis for the 2010 California Fire Code
} 
- 6.12: Describes the gaseous hydrogen $\left(\mathrm{GH}_{2}\right)$ gas detection, and requires that such equipment shall be listed or approved. This section also covers calibration, maintenance and record keeping requirements

\section{Chapter 7: Gaseous Hydrogen $\left(\mathrm{GH}_{2}\right)$}

- 7.1: Leak detection requirements and emergency shutdown

- 7.3.2: $\mathrm{Bulk} \mathrm{GH}_{2}$ systems storage detection system requirements

\section{Chapter 10: $\mathbf{G H}_{2}$ Vehicle Dispensing Facilities}

- 10.2: Detection requirements for hydrogen dispensers

- 10.3: System maintenance requirements, including those for the detection devices. Fire protection requirements require that dispensing equipment be provided with gas detectors. Indoor public dispensing units shall a continuous mechanical ventilation system or a mechanical controlled ventilation system activated by a continuously monitoring hydrogen detection system. Alarm levels and interface requirements for the gas detection system are defined.

\section{Chapter 11: $\mathbf{L H}_{2}$ (Liquid Hydrogen) Fueling Facilities}

- 11.3: Dispensing equipment shall be provided with gas detectors, leak detectors, and flame detectors such that fire and gas can be detected at any point on the equipment. Gas detection equipment for dispensing shall be listed or approved

\section{Chapter 12: Hydrogen Fuel Cell Power Systems}

- 12.3: For indoor installations of fuel cell power systems, gas detection system, combustible gas detector(s) shall be installed in the fuel cell power system enclosure, the exhaust system, or the room that encloses the fuel cell power system

- 12.4: Storage - Gas detection shall be located outside a building that houses a power system.

\section{Chapter 13: Hydrogen Generation Systems}

- 13.3: Combustible gas detection shall be installed

Reserved Chapters ${ }^{3}$

\section{Chapter 17: Parking Garage (reserved)}

Chapter 18: Road Tunnels (reserved)

Chapter 19: Repair Garage (reserved)

\section{Chapter 20: Fuel Blends (reserved)}

\footnotetext{
3 "Reserved" chapters have not yet been incorporated into NFPA 2, but may be at some point. These may include hydrogen detection requirements.
} 